\title{
Significados do Dinheiro e do Trabalho: Um Estudo com Operários da Construção de Edificações de Belo Horizonte
}

\author{
Sabrina Cavalcanti Barros ${ }^{1}$ \\ Universidade Federal de Minas Gerais \\ Livia de Oliveira Borges ${ }^{2}$ \\ Universidade Federal de Minas Gerais
}

\begin{abstract}
RESUMO
Os significados do dinheiro e do trabalho são fenômenos multidimensionais, imbuídos de aspectos contraditórios forjados no contexto contemporâneo do sistema capitalista. Objetivamos, então, explorar a relação entre os dois fenômenos na construção de edificações. Desenvolvemos a pesquisa com 302 operários, aplicando questionários e realizando entrevistas. Às respostas dos questionários aplicamos técnicas estatísticas descritivas (frequência e médias) e inferenciais (análise de cluster e ANOVA). A interpretação das entrevistas apoiou a compreensão dos resultados das análises anteriores. Entre os resultados encontrados, destacamos: os valores coletivistas incorporados aos padrões de significado do dinheiro (PSD); a tendência dos participantes do padrão do significado do trabalho (PST) indiferente expressivo em apresentar o PSD coletivista expressivo e dos participantes do PST otimista em apresentar menos frequentemente o PSD conflitante.
\end{abstract}

Palavras-chave: significado do dinheiro; significado do trabalho; operários da construção de edificações.

\begin{abstract}
Meanings of money and work: a study with construction workers of buildings in Belo Horizonte

The meanings of money and work are multidimensional phenomena imbued with contradictory aspects that are forged in the contemporary context of the capitalist system. Then, weaimed to explore the relationship between the phenomena in the construction of buildings. We developed the research with 302 workers applying questionnaires and interviews. To the answers of questionnaires, we were applied descriptive (frequency and mean) and inferential (cluster analysis and ANOVA) statistics techniques. The interpretation of interviews supports an understanding of antecedents analysis. Among the results, the followers made salient: the collectivist values incorporated in the pattern of money meanings (PMM); the tendency from participants of Indifferent Expressive pattern of work meaning (PWM) to present Expressive Collectivist PMM; and from participants with Optimist PWM presenting less frequently the Conflicting PMM.
\end{abstract}

Keywords: Money Meaning; Work Meaning; Workers of Building Construction.

O trabalho e o dinheiro ocupam papel relevante nas sociedades capitalistas (Marx, 1890, 1980; Simmel, 1907, 2005) devido, entre outras razões, às transformações sofridas por ambos os fenômenos (p. ex., a divisão do trabalho; a cunhagem de moeda, as políticas monetárias). As crises estruturais que vêm se instalando, a exemplo da redução na quantidade de trabalho e de empregos formais especialmente no setor industrial, não suplantaram o caráter estruturante do trabalho na vida das pessoas, fato observado por Antunes (1995), para quem o trabalho, nos moldes capitalistas, segue sendo o meio de obtenção das condições materiais necessárias (salário/remuneração) para o desenvolvimento das demais esferas de vida.

Para além das dinâmicas de mercado, o trabalho e o dinheiro coexistem com uma multiplicidade de significados construídos pelos indivíduos a partir de suas experiências cotidianas, carregando em seu bojo conotações contraditórias, o que evidencia a complexidade com que tais fenômenos são constituídos. Tais significados simbólicos, segundo Bruner (1997), são atos essenciais na organização e orientação da socialização e, sendo dinâmicos, dependem do contexto para sua compreensão.

Estudos que focalizam o processo de construção de significados, a exemplo dos temas tratados nesta pesquisa, têm-se ampliado no campo da Psicologia Social, devido, entre outros fatores, à influência da abordagem cognitiva, a qual reinseriu no referido campo a discussão sobre a mediação entre estímulos e comportamen- 
tos pelas cognições e o caráter sociocultural de tais cognições (Borges, 1998b; Bruner, 1997). Um exemplo do impacto dos estudos sobre a cognição pode ser observado na análise de Katzell (1994), o qual sinalizou tal abordagem como uma das tendências no desenvolvimento da Psicologia do Trabalho e das Organizações, destacando o interesse em compreender como as pessoas processam as informações recebidas no contexto laboral e como esse conhecimento tem sido aplicado na prática.

Tendo em vista essas considerações, objetivamos explorar as relações entre os significados do dinheiro e do trabalho para operários da construção de edificações. Durante o desenvolvimento das atividades de campo, tal ocupação vivenciava um período de aquecimento econômico (DIEESE, 2011), representando, dentre outros aspectos, aumento na criação de postos de emprego formais (PED, 2012) e dificuldades em contratar mão de obra especializada (Mello \& Amorim, 2009). Apesar de economicamente atrativa, essa ocupação ainda apresenta precárias condições de trabalho (p. ex., condições insalubres e adversas, jornada de trabalho extensa), além de os trabalhadores sofrerem estigmas devido à falta de qualificação e/ou instrução e do esforço físico tomado como principal ferramenta de trabalho, sobretudo no subsetor de edificações (Borges \& Peixoto, 2011; P. H. F. Santos, 2010; Souza, 1983).

Se as atribuições de significados ao trabalho e ao dinheiro afetam a vida cotidiana, como já mencionado, atingir o objetivo da presente pesquisa significa refletir sobre o modo como os operários vivenciam, interpretam e interagem. Pode, então, contribuir com a busca de soluções para os problemas mencionados, bem como incentivar a reflexão e/ou a avaliação das estratégias e estilos de gestão, as relações interpessoais no trabalho e a organização dos próprios trabalhadores como um coletivo.

\section{Significados do trabalho}

A literatura converge em apresentar a publicação da equipe MOW (1987) - Meaning of Work International Research Team - como referência seminal nos estudos sobre o significado do trabalho (Bastos, Pinho, \& Costa, 1995; Borges \& Tamayo, 2001; Cifre, Martínez, Llorens, \& Salanova, 2001; Harpaz \& Meshoulam, 2010). Conceituando o fenômeno como determinado por um conjunto de fatores que interatuam nos níveis individual e social, a equipe identificou três facetas (centralidade do trabalho, normas societais, resultados valorados), além de padrões (p. ex., instrumentalidade, centralidade e expressão) obtidos pela combinação dos escores nos fatores das facetas citadas e compartilhados por grupos de participantes.

A partir dos achados da equipe MOW (1987), pesquisas posteriores apresentaram resultados que corroboraram a centralidade do trabalho, evidenciando-a como a segunda esfera de vida mais importante (atrás de família). Convergiram também na identificação de significados como aspectos econômicos, autorrealização (Álvaro, Bergère, Crespo, Torregrosa, \& Garrido, 1995), aprendizado (Dakduk, González, \& Montilla, 2008), ser gratificante e gerar satisfação (Ardichvili, 2005). No entanto, são divergentes em organizar tais significados em facetas. No Brasil, Soares (1992) não encontrou a mesma estrutura do modelo da equipe MOW, não discriminando normas societais e resultados valorados.

Outros pesquisadores (p. ex., Bastos et al., 1995; Borges, Tamayo, \& Alves Filho, 2005; Brief \& Nord, 1990) ressaltaram que tal modelo não considerou as especificidades dos países envolvidos, perdendo o caráter contextual e processual inerente aos significados. Borges e Tamayo (2001) elaboraram um modelo de estudo sobre os significados do trabalho, definindo-o como um fenômeno processual, que varia no nível individual (o que a pessoa vivencia) e coletivo (o que é compartilhado socialmente), e considerando o contexto em que essas experiências ocorrem. Permite, portanto, uma aproximação maior da realidade brasileira.

Essa atenção ao contexto levou estudos antecedentes no Brasil a revelar significados do trabalho como expressão de saúde, desumanização, exploração, braçal, árduo, humilhante (Borges, 1996) e penosidade (Sato, 1993). Esses estudos corroboram outros (Aktouf, 1986; Martin-Baró, 1990) que sublinham o caráter contraditório e dialético do trabalho, significando, ao mesmo tempo, exploração e alegria ou sofrimento e prazer. As considerações sobre esses conteúdos apontaram, em última análise, a insuficiência das facetas eleitas pela equipe MOW (1987) para abarcá-los.

O modelo de Borges e Tamayo (2001) apresenta, então, quatro facetas: centralidade do trabalho (importância do trabalho, quando comparado à família, ao lazer, à comunidade e à religião), atributos valorativos (como o trabalho deve ser), atributos descritivos (como o trabalho é) e hierarquia dos atributos (organização dos fatores encontrados, conforme sua ordem de importância). Os autores mantiveram a primeira faceta da equipe MOW (1987) e assumiram que as normas soci- 
etais fazem parte dos atributos valorativos e descritivos.

Baseados no referido modelo, pesquisadores têm explorado os significados do trabalho no Brasil em diferentes contextos. Vilela (2003), por exemplo, percebeu uma idealização sobre o trabalho valorizado pelos estudantes em início de curso superior e uma tendência a perceber o trabalho como responsabilidade e fonte de dignidade. Varella e Borges (2012) analisaram dois momentos de pesquisa em setor bancário (1999 e 2005) e observaram uma maior valorização do trabalho como fonte de autoexpressão e realização pessoal e maior percepção referente à recompensa econômica, à responsabilidade e às condições de trabalho. C. A. Santos (2006) encontrou elevada centralidade do trabalho para policiais e uma maior valorização de seu papel instrumental e de sentir-se autorrealizado e útil à sociedade. Borges e Yamamoto (2010) identificaram, entre os psicólogos brasileiros, alta centralidade do trabalho e tendência a definir o que seja um trabalho ideal (ou de qualidade) com base em múltiplos critérios e pôr ênfase na categoria humanização-sociabilidade do trabalho real.

Os vários aspectos levantados acerca de como as pessoas percebem o trabalho nos mais diversos contextos demonstram a dinamicidade e a processualidade do fenômeno. As pesquisas também revelaram aspectos em comum nos significados do trabalho entre os diferentes contextos sociais, no que diz respeito à sua centralidade e aos aspectos econômicos. Esses aspectos compartilhados são provavelmente as vivências das pessoas sob o sistema capitalista. Embora os significados do trabalho não se reduzam aos aspectos econômicos, estes estão interligados aos demais.

\section{Significados do dinheiro}

Os estudos sobre os significados do dinheiro surgiram de maneira mais estruturadana década de 1970 (Moreira, 2000), e destacam-se como referências antecedentes quatro modelos de pesquisa dos seguintes autores: 1) Wernimont e Fitzpatrick (1972); 2) Yamauchi e Templer (1982); 3) Furnham (1984); e 4) Tang (1993). Tais modelos compartilham similaridades no que se refere aos descritores simbólicos (p. ex. aceitabilidade social, fracasso, poder e prestígio, desconfiança), ao caráter ambíguo das construções simbólicas associadas ao dinheiro (aspectos positivos e negativos) e/ou à incorporação das contradições presente no capitalismo (exploração e consumo).

No entanto, como observa Moreira (2000), esses modelos foram apresentados por seus autores com insu- ficiente esclarecimento sobre seus fundamentos teóricos. O mesmo acontece ao relatarem a construção de instrumentos de mensuração do significado do dinheiro, uma vez que não foram considerados dados empíricos para tal construção, impossibilitando, assim, o afloramento da percepção de senso comum das populações pesquisadas. Tais observações conduziram a autora a propor um modelo de pesquisa que superasse as limitações detectadas nos estudos anteriores e também que considerasse as contribuições de outras áreas das ciências sociais.

Entendendo o significado do dinheiro como um construto multifatorial e dialético, Moreira (2000) desenvolveu um modelo identificando nove componentes situados em dois polos de análise, um positivo (progresso, cultura, estabilidade, prazer) e outro negativo (desigualdade, desapego, conflito, sofrimento), tendo o componente poder característica simultaneamente positiva (prestígio social) e negativa (dominação). Tal modelo reconfigurou e ampliou o nível de análise, permitindo a exploração dos níveis macros (p. ex., desigualdade) ao microssociais do significado do dinheiro (p.ex., prazer, sofrimento). Em pesquisa com brasileiros das cinco regiões geográficas do Brasil, Moreira (2002) encontrou evidências empíricas que corroboraram a estrutura do modelo proposto e constatou que os componentes que relacionam o dinheiro ao nível coletivo (desigualdade, progresso e cultura) assumiram posições mais elevadas que os outros, indicando que o dinheiro, para o brasileiro, assume caráter de preocupação social.

A partir desse modelo (Moreira, 2000), pesquisas posteriores vêm apresentando distintas prevalências dos seus componentes. Como exemplo, Borsato, Gomes, Pimenta, Carvalho e Ribeiro (2010) concluíram que pessoas adimplentes tendem a perceber o dinheiro como um meio de estabilidade, enquanto os inadimplentes, como poder e obsessão. Oliveira (2010), por sua vez, verificou que a crença na obtenção de felicidade por meio do dinheiro é um dos aspectos mais influenciadores na escolha profissional de estudantes universitários. Távora (2003) explorou as relações entre os significados do dinheiro e do salário para funcionários de transporte coletivo urbano utilizando uma versão reduzida do instrumento de autoria de Moreira (2002) e revisto por Moreira, Caldas e Atayde (2002). Essa versão apresentou os mesmos polos, mas com composição fatorial menor. Távora observou que, para os motoristas e cobradores, o dinheiro é visto como meio de ajudar as pessoas (altruísmo) e como fonte de desigualdade social (desigualdade). 
Esses estudos, de um modo geral, revelam o caráter ambíguo (aspectos positivos e negativos), polimorfo (várias facetas) e motivador (meio de troca) do dinheiro, fazendo com que ele seja definido, em parte, pela experiência cotidiana das pessoas. As diferentes percepções encontradas nas pesquisas corroboram os estudos de Bruner (1997), que entende o processo de atribuição de significados como algo dinâmico, já que está exposto às transformações inerentes às interações sociais. Observamos, contudo, uma maior concentração de participantes com nível de instrução mais elevado (ensino médio e superior) na maior parte das pesquisas encontradas sobre o tema. Isso pode refletir a realidade de países mais desenvolvidos economicamente, mas não a de países como o Brasil, que ainda têm um contingente elevado de pessoas com baixo nível de instrução. Estudar esse tema no contexto da construção de edificações, então, adiciona relevância, na medida em que alcança essa parcela da população.

\section{MÉTODO}

A pesquisa de campo foi realizada em duas construtoras de edificações de Belo Horizonte. A escolha foi feita a partir de levantamento prévio das construtoras localizadas em Belo Horizonte e que demonstraram interesse na pesquisa. $\mathrm{O}$ acesso a uma delas foi construído com o apoio do Sindicato dos Trabalhadores da Construção Civil da capital mineira. Trata-se de uma empresa privada, com fins lucrativos, consolidada no mercado, cuja atuação abrange a construção, a compra e a venda de imóveis. O contato com a outra construtora foi realizado diretamente com seus dirigentes. Ela é caracterizada como uma prestadora de serviços de construção civil a uma instituição pública, oferecendo suporte estrutural para o desenvolvimento das atividades dessa instituição. Seus operários foram, então, os participantes da pesquisa, como expomos a seguir.

\section{Participantes}

Participaram 302 operários das duas construtoras já referidas. Para caracterização da amostra, levantamos aspectos sociodemográficos sem perder de vista a preservação do anonimato dos participantes. Eles são predominantemente do sexo masculino (94\%), com idade entre 18 e 69 anos $(M=34,86$; $D P=10,65)$, tempo médio de 10,86 anos $(\mathrm{DP}=10,22)$ de trabalho no setor da construção civil e de 1,92 ano ( $\mathrm{DP}=2,62)$ no emprego atual. Essas duas últimas médias sinalizam a alta rotatividade no emprego. A maioria $(53,7 \%)$ possui grau de instrução até o ensino fundamental incompleto, e
$33,1 \%$, entre o ensino médio incompleto e completo. Essa última proporção provavelmente reflete as tendências de absorção de quadro com novo perfil no contexto de aquecimento econômico do setor.

\section{Instrumentos}

Os instrumentos adotados foram o Inventário de Significado do Trabalho (IST), uma questão sobre centralidade do trabalho e a Escala de Significado do Dinheiro (ESD II), apresentando, todos eles, pesquisas anteriores sobre suas características psicométricas. Apesar disso, e considerando a dinamicidade do significado do trabalho, foi desenvolvida nova pesquisa (Borges e Barros, 2015) sobre as evidências de validade do IST com uma amostra de 411 operários da construção de edificações, dentre os quais se inclui a amostra da presente pesquisa. O IST é composto de 68 frases afirmativas acerca do trabalho. A cada item, o participante apresenta duas respostas, conforme duas escalas (impressa com cores graduais) do tipo Likert de cinco pontos, variando de 0 (branco, em ambos os atributos) a 4 (verde-escuro para os atributos valorativos e azul-escuro para os descritivos). A estratégia de escala impressa com diferenciação por cores foi adotada por analogia com o material utilizado em pesquisa antecedente com trabalhadores com baixo nível de instrução formal (Borges \& Pinheiro, 2002).

Naquela pesquisa (Borges \& Barros, 2015), os tipos de atributos identificados (tabela 1) (Smallest Space Analysis - SSA) apresentaram consistência, com coeficiente alfa de Cronbach variando entre 0,65 e 0,86 para os atributos valorativos e entre 0,68 e 0,84 para os descritivos. Esclarecemos que, por uma opção de solução mais parcimoniosa, os tipos descritivos identificados na tabela 1 são condensações daqueles dez identificados por Borges e Barros. Por consequência, os alfas na citada tabela foram estimados para a presente pesquisa.

A pergunta que corresponde à faceta centralidade do trabalho é de autoria da equipe MOW (1987), adaptada e traduzida para o português por Soares (1992). Nela, o participante ordena de forma decrescente o nível de importância das cinco esferas de vida (trabalho, religião, família, comunidade e lazer). Utilizamos a mesma estratégia de recurso não verbal na forma de figuras que representam cada uma dessas esferas de vida, desenvolvidas e adotadas por Borges (1998a).

A ESD II é uma adaptação realizada por Moreira et al. (2002) do questionário desenvolvido por Moreira (2000), contendo 60 frases afirmativas sobre o dinheiro, cujas respostas são dadas mediante uma escala do tipo 
Tabela 1

Tipos dos atributos valorativos e descritivos dos significados do trabalho

\begin{tabular}{|c|c|}
\hline \multicolumn{2}{|r|}{ Tipos de atributos valorativos } \\
\hline & O trabalho deve: \\
\hline $\begin{array}{l}\text { TV1 - Fonte de realização e } \\
\text { independência econômica } \\
(a=0,73)\end{array}$ & $\begin{array}{l}\text { Ser prazeroso, estimulando o crescimento profissional, social e pessoal, trazendo satisfação tanto na } \\
\text { execução como no retorno recebido (reconhecimento e independência). }\end{array}$ \\
\hline $\begin{array}{l}\text { TV2 - Expressão de respeito } \\
\text { e de acolhimento }(a=0,86)\end{array}$ & $\begin{array}{l}\text { Promover um ambiente de confiança, respeito e qualidade, em que o trabalhador se sinta valorizado, } \\
\text { sendo servido de assistência e recursos necessários para o bom desempenho das tarefas. }\end{array}$ \\
\hline $\begin{array}{l}\text { TV3 - Fonte de desafio e } \\
\text { ocupação }(a=0,68)\end{array}$ & $\begin{array}{l}\text { Ser desafiante e exercido com consciência e esforço (intelectual), sendo o meio de ocupação na vida } \\
\text { das pessoas. }\end{array}$ \\
\hline $\begin{array}{l}\text { TV4 - Autoafirmativo } \\
(a=0,65)\end{array}$ & $\begin{array}{l}\text { Gerar no próprio trabalhador o reconhecimento de suas qualidades, responsabilidades e méritos, além } \\
\text { de uma conscientização sobre o contribuir para o crescimento da sociedade (outros são beneficiados). }\end{array}$ \\
\hline $\begin{array}{l}\text { TV5 - Representante de } \\
\text { dureza }(a=0,74)\end{array}$ & $\begin{array}{l}\text { Exigir esforço físico, ritmo mais acelerado e mais repetitivo, trazendo uma ideia de ser pesado, exigente } \\
\text { fisicamente. }\end{array}$ \\
\hline $\begin{array}{l}\text { TV6 - Desumanizante e } \\
\text { desgastante }(a=0,76)\end{array}$ & $\begin{array}{l}\text { Ser desgastante, exigindo agilidade e sobrecarga e também desumano, à medida que explora, } \\
\text { subvaloriza e discrimina. }\end{array}$ \\
\hline \multicolumn{2}{|r|}{\begin{tabular}{|l} 
Tipos de atributos descritivos \\
\end{tabular}} \\
\hline & 0 trabalho é (ocorre): \\
\hline $\begin{array}{l}\text { TD1 - Fazer esforço corporal } \\
\text { e desumanizar-se }(a=0,80)\end{array}$ & $\begin{array}{l}\text { Visto como desgastante implicando rapidez e acentuado esforço físico, além de representar exploração, } \\
\text { subvalorização e discriminação. }\end{array}$ \\
\hline TD2 - Ocupar-se $(a=0,68)$ & $\begin{array}{l}\text { Uma ocupação, por meio da qual se preenche o tempo e que traz a ideia de saúde implicada na } \\
\text { execução das atividades, sendo também um meio de inclusão social (sentir-se gente). }\end{array}$ \\
\hline $\begin{array}{l}\text { TD3 - Ser responsável, } \\
\text { desafiar-se e crescer } \\
\text { economicamente }(a=0,84)\end{array}$ & $\begin{array}{l}\text { Fonte de crescimento pessoal, profissional e social, permitindo que o trabalhador se sinta digno, } \\
\text { responsável e capaz de executar bem suas tarefas, com criatividade e empenho. }\end{array}$ \\
\hline $\begin{array}{l}\text { TD4 - Realizar-se e sentir-se } \\
\text { útil }(a=0,79)\end{array}$ & $\begin{array}{l}\text { Fonte de realização e prazer, à medida que oferece oportunidades, condições e assistências } \\
\text { necessárias, gerando confiança, comprometimento e contribuição social (outros se beneficiam). }\end{array}$ \\
\hline $\begin{array}{l}\text { TD5 - Ser reconhecido e } \\
\text { tratado com justiça }(a=0,83)\end{array}$ & $\begin{array}{l}\text { Visto como importante e necessário à humanidade, cujo ambiente e assistência adequados garantem } \\
\text { igualdade de direitos, reconhecimento pelos esforços e relações amistosas. }\end{array}$ \\
\hline
\end{tabular}

Likert, variando de 1, "discordo fortemente", a 5, "concordo fortemente". Na presente pesquisa, foi utilizada uma escala impressa de cores graduais em tom azul para auxiliar os respondentes, a exemplo da estratégia utilizada para a aplicação do IST. Apesar de a ESD II contar com estudos antecedentes sobre suas evidências de validade, aplicamos, seguindo as estratégias adotadas por Távora (2003) e Moreira (2000), análise dos componentes principais, com rotação varimax e com critério de carga fatorial maior que 0,40. Encontramos os mesmos componentes (tabela 2), que em conjunto explicaram 40,96\% da variância e apresentaram coeficientes alfa de Cronbach variando entre 0,61 e 0,86 .

\section{Procedimento de coleta e análise de dados}

Aplicamos os questionários individualmente, no local de trabalho dos participantes, e com o auxílio de um dispositivo de mão informatizado (Pocket $P C$ ) para registro de respostas. Esse procedimento e o uso já mencionado das escalas impressas em cores facilitaram a participação dos trabalhadores, visto que não dependiam da leitura/escrita para responder.

Transferimos as respostas aos questionários para o banco de dados do Statistical Package of Social Sciences (SPSS), a partir do qual realizamos análises descritivas (frequências e médias) para caracterizar a amostra e estatísticas inferenciais (análise de cluster e ANOVA). Sobre o significado do trabalho, para este artigo,consideramos três facetas: centralidade do trabalho e atributos valorativos e descritivos.

Realizamos também entrevistas semiestruturadas com sete operários das mesmas construtoras com um mínimo de seis meses de tempo de serviço. Essas entrevistas tratavam da visão dos participantes sobre as 
Tabela 2

Componentes dos significados do dinheiro

\begin{tabular}{|c|c|}
\hline \multicolumn{2}{|r|}{ Componentes dos significados do dinheiro } \\
\hline $\begin{array}{l}\text { Prazer } \\
\left(r^{2}=16,89 \text { e } a=0,86\right)\end{array}$ & $\begin{array}{l}\text { Traz a ideia de que o dinheiro é fonte de felicidade, de prazer, de harmonia e de satisfação nos } \\
\text { relacionamentos em geral. }\end{array}$ \\
\hline $\begin{array}{l}\text { Conflito } \\
\left(r^{2}=7,19 \text { e } a=0,81\right)\end{array}$ & $\begin{array}{l}\text { O dinheiro é percebido como gerador de desconfiança, inveja, desavença e traições nas relações } \\
\text { interpessoais. }\end{array}$ \\
\hline $\begin{array}{l}\text { Sofrimento } \\
\left(r^{2}=5,61 \text { e } a=0,74\right)\end{array}$ & Transmite a ideia de que o manejo do dinheiro traz angústias, sensação de impotência e de culpa. \\
\hline $\begin{array}{l}\text { Desigualdade } \\
\left(r^{2}=4,56 \text { e } a=0,72\right)\end{array}$ & O dinheiro é percebido como fonte de exclusão e dominação social. \\
\hline $\begin{array}{l}\text { Altruísmo } \\
\left(r^{2}=3,48 \text { e } a=0,78\right)\end{array}$ & $\begin{array}{l}\text { O dinheiro é visto como meio de crescimento através do progresso científico/tecnológico, do desenvolvimento } \\
\text { das artes e da cultura popular. }\end{array}$ \\
\hline $\begin{array}{l}\text { Transcendência } \\
\left(r^{2}=3,22 \text { e } a=0,61\right)\end{array}$ & $\begin{array}{l}\text { Ligado à espiritualidade, o dinheiro é percebido como meio de ajudar os desfavorecidos, uma maneira de } \\
\text { exercitar a fé e o amor ao próximo. }\end{array}$ \\
\hline
\end{tabular}

características gerais da organização e suas condições de trabalho. Para efeito do presente artigo, as respostas dos operários foram analisadas com o intuito de apoiar a compreensão e/ou interpretação das respostas aos questionários.

\section{RESULTADOS E DISCUSSÃO}

\section{Significados do dinheiro}

Inicialmente, realizamos a identificação dos componentes dos significados do dinheiro e de suas respectivas médias, encontrando em transcendência e conflito as médias mais elevadas e em prazer e sofrimento, as mais baixas. Em seguida, aplicamos a análise de variância (ANOVA) de medidas repetidas. O teste post hoc (Bonferroni) demonstrou que quatro dos componentes contam com níveis de concordância diferentes para os operários, e dois deles (retângulo pontilhado na tabela 3) encontram-se em um mesmo nível.
Os cinco primeiros componentes apresentaram uma concentração de respostas nos intervalos mais elevados (concordo e concordo fortemente), indicando um consenso entre os participantes sobre as conotações que tais componentes representam. Destes, transcendência ocupou o primeiro lugar na ordem de prioridade, o que destaca o dinheiro como meio de ajudar o próximo e de expressar a fé religiosa. Esse resultado foi corroborado nas entrevistas, quando um operário retratou sua religiosidade como o balizador do dever moral para com o próximo e fonte de proteção divina.

Eu tive um fundamento religioso muito forte, eu fui testemunha de Jeová durante quase 14 anos da minha vida.

Então, estudei realmente a fundo a Bíblia (...), isso é ser religioso. É você saber o que é certo, tentar de qualquer maneira seguir aquilo que é certo e desviar daquilo que tá errado, que você sabe que tá errado (...) (Entrevista 15 Operário).

Ocupando um mesmo patamar de concordância encontram-se altruísmo e desigualdade, refletindo a ideia

Tabela 3

Média e desvio padrão dos escores dos componentes dos significados do dinheiro e porcentagens por intervalo de resposta ( $N=302)$

\begin{tabular}{|c|c|c|c|c|c|c|}
\hline \multirow[t]{2}{*}{ Componente } & \multirow[t]{2}{*}{ Média } & \multirow{2}{*}{$\begin{array}{l}\text { Desvio } \\
\text { Padrão }\end{array}$} & \multicolumn{4}{|c|}{$\begin{array}{l}\text { Frequência de participantes por intervalo de escores nos } \\
\qquad \text { componentes (\%) }\end{array}$} \\
\hline & & & $x \leq 2$ & $2<x \leq 3$ & $3<x \leq 4$ & $x>4$ \\
\hline C6 - Transcendência & 4,37 & 0,64 & 0,7 & 4,3 & 23,5 & 71,5 \\
\hline C2 - Conflito & 4,14 & 0,68 & 0,7 & 7,6 & 27,5 & 64,2 \\
\hline C5 - Altruísmo & 3,86 & 0,86 & 5,0 & 12,3 & 37,7 & 45,0 \\
\hline C4 - Desigualdade & 3,82 & 0,92 & 5,6 & 17,2 & 33,8 & 43,4 \\
\hline C1 - Prazer & 3,64 & 0,76 & 2,0 & 19,9 & 45,7 & 32,5 \\
\hline C3 - Sofrimento & 2,70 & 0,84 & 25,2 & 41,4 & 27,5 & 6,0 \\
\hline
\end{tabular}


de que o dinheiro é, ao mesmo tempo, fonte de progresso e de exclusão e dominação social. Em último lugar, encontra-se o sofrimento, cuja distribuição dos participantes nos intervalos evidencia maior divergência entre eles quanto a perceber o dinheiro como gerador de sofrimento: $41,4 \%$ assumem uma posição neutra, $25,2 \%$ discordam e 27,5\% concordam.

Essa configuração, seguindo os eixos norteadores dos significados do dinheiro (Moreira, 2000; Távora, 2003), organiza os polos (positivo e negativo) de maneira intercalada na ordem de concordância, demonstrando uma visão dialética dos operários sobre o dinheiro, sendo tal constatação mais clara no terceiro nível. Ademais, entre a primeira e a terceira ordens de concordância situam-se os componentes que descrevem o dinheiro em um contexto social mais amplo (transcendência e desigualdade) e em um nível intermediário entre o macro e o micro (conflito e altruísmo), aproximando-se dos resultados de Moreira (2002), em que o dinheiro é visto ao nível da coletividade.

Para uma compreensão sistêmica desses resultados, a exemplo da literatura do significado do trabalho (MOW, 1987; Borges, 1998a), identificamos os padrões dos significados do dinheiro. Por meio da técnica de análise de clusters, encontramos quatro grupos distintos que compartilham modos semelhantes de combinação dos escores dos seis componentes dos significados do dinheiro (tabela 4).

A visão coletivista dos significados do dinheiro manteve-se nos quatro padrões identificados, sendo uma tendência da amostra discutida anteriormente. Nos grupos em que tal visão é menos acentuada, as conotações de conflito e de pessimismo tornaram-se mais evidentes. Os aspectos coletivistas relacionam-se com a ideia de ser solidário, tendo a espiritualidade (religião) como ponto de apoio, e de ser uma via de crescimento e progresso do país, em seus amplos contextos. Tais conotações coadunam-se com o cotidiano dos operários, cujos baixos salários implicam uma maior preocupação com a sobrevivência. Ser solidário com o outro é uma forma de ajudar e, ao mesmo tempo, ser ajudado. Cockell (2008) ressaltou a importância das redes sociais informais (p. ex., família nuclear e extensa, amigos e associações na comunidade) como ferramenta útil para provisão de recursos de operários que se encontram em vulnerabilidade social.

\section{Significados do trabalho}

À semelhança do que realizamos na seção anterior, para os atributos valorativos e descritivos, identifica-

Tabela 4

Padrões dos significados do dinheiro

\begin{tabular}{|c|c|c|}
\hline $\begin{array}{c}\text { Padrões dos } \\
\text { significados do } \\
\text { dinheiro }\end{array}$ & $\mathbf{N}^{*}$ & Descrição \\
\hline Coletivista Expressivo & 102 & $\begin{array}{l}\text { É o grupo que possui os escores mais elevados em todos os componentes, quando comparado com } \\
\text { os demais, sendo também o que apresenta a mesma configuração demonstrada na ordem de } \\
\text { prioridades dos componentes dos significados do dinheiro. Destacam-se Transcendência, Conflito, } \\
\text { Altruísmo e Desigualdade. As contradições por trás do dinheiro e os sentidos coletivistas são } \\
\text { bastante expressivos. }\end{array}$ \\
\hline Coletivista & 73 & $\begin{array}{l}\text { Esse grupo atribui maior escore para o componente Transcendência e o menor para Sofrimento, } \\
\text { sendo este último também o menor em relação aos demais grupos. A conotação coletivista do } \\
\text { dinheiro é mais prevalente que os demais sentidos. Consideram o dinheiro como um meio de ajuda } \\
\text { social e de progresso do país. }\end{array}$ \\
\hline Conflitante & 46 & $\begin{array}{l}\text { Para esse grupo, o componente Conflito recebeu maior destaque. Comparando-o com os demais, é o } \\
\text { grupo que menos percebe o dinheiro como fonte de Altruísmo e Prazer. Consideram o dinheiro como } \\
\text { meio de ajuda social, ao mesmo tempo em que o percebem de forma negativa interferindo nas } \\
\text { relações interpessoais. }\end{array}$ \\
\hline Pessimista & 75 & $\begin{array}{l}\text { Nesse grupo, os escores mais elevados foram para os componentes Conflito e Desigualdade, embora } \\
\text { confiram sentido transcendente ao dinheiro. Em outras palavras, é o grupo para quem os aspectos } \\
\text { negativos por trás do dinheiro são mais prevalentes, mas reconhecem que por meio dele é possível } \\
\text { ajudar quem necessita. }\end{array}$ \\
\hline
\end{tabular}

${ }^{*} \mathrm{~N}$ (Número de participantes) 
mos os tipos que compõem cada um desses atributos, bem como suas respectivas médias. Em seguida, aplicamos a análise de variância (ANOVA) de medidas repetidas. O teste post hoc (Bonferroni) demonstrou níveis de concordância diferentes para os operários em relação a cada tipodos atributos valorativos e descritivos (tabela $5)$.

Nos quatro primeiros tipos valorativos na tabela 5 , além das maiores médias, observamos uma concentração de respondentes no intervalo de escores mais elevado, indicando a tendência a um consenso entre os participantes sobre o valor que tais aspectos representam para eles. Entre esses tipos, a expressão de respeito e de acolhimento (TV2) foi o mais valorizado, o qual evidencia o desejo do operário de sentir-se respeitado e acolhido enquanto trabalhador. A importância atribuída a esse tipo também se expressa na fala de um dos entrevistados:

(...) é a satisfação de todos os dias acordar e ver que sou bem tratado por todos. Tem o encarregado que gosta do meu serviço, tem uns amigos aí que me apoia (...) E isso vale muito porque, se não tiver união, não tem força nenhuma (Entrevista 13 - Operário).

Nos dois tipos restantes, cujas médias são menores, os participantes apresentam escores mais dispersos do que nos tipos anteriormente mencionados. Há, entretanto, em representante de dureza (TV5), uma tendência a concentração nos intervalos intermediários, enquanto em desumanizante e desgastante (TV6) essa tendência se dá nos intervalos inferiores. Em pesquisa realizada por Borges (1998a) com operários da construção civil, as características de um trabalho duro, desumanizante e desgastante foram bastante valorizadas. $\mathrm{Na}$ atual amostra, observamos uma tendência de enfraquecimento dessa valorização, sugerindo uma mudança no perfil de trabalhadores, embora ainda haja certa resignação por parte destes quanto à vivência no dia a dia. Portanto, para essa amostra, o trabalho ser desumanizante e desgastante provavelmente está deixando de ser um atributo valorativo.

Nos cinco atributos descritivos, há uma tendência para escores mais baixos quando comparados aos valorativos, justificável por se tratar de atribuições que descrevem a realidade do trabalho. Nos três primeiros tipos, segundo a magnitude das médias, observamos uma concentração de respondentes no intervalo mais elevado, indicando uma tendência de consenso entre os operários sobre tais tipos, estando em ocupar-se (TD2)

Tabela 5

Média e desvio padrão dos escores dos tipos valorativos e descritivos dos significados do trabalho e porcentagens por intervalo de resposta $(n=296)^{*}$

\begin{tabular}{|c|c|c|c|c|c|c|}
\hline \multirow[t]{2}{*}{ Tipos } & \multirow[t]{2}{*}{ Média } & \multirow{2}{*}{$\begin{array}{l}\text { Desvio } \\
\text { Padrão }\end{array}$} & \multicolumn{4}{|c|}{$\begin{array}{l}\text { Frequência de participantes por intervalo de } \\
\text { escores nos tipos (\%) }\end{array}$} \\
\hline & & & $x \leq 1$ & $1<x \leq 2$ & $2<x \leq 3$ & $x>3$ \\
\hline \multicolumn{7}{|c|}{ Atributos Valorativos $(F=1.750,44$ para $p<0,001)$} \\
\hline TV2 - Expressão de Respeito e de Acolhimento & 3,81 & 0,25 & - & - & 1,7 & 98,3 \\
\hline TV1 - Fonte de Realização e Independência Econômica & 3,75 & 0,24 & - & - & 1,7 & 98,3 \\
\hline TV4 - Autoafirmativo & 3,67 & 0,35 & - & - & 6,1 & 93,9 \\
\hline TV3 - Fonte de Desafio e Ocupação & 3,58 & 0,40 & - & 0,3 & 8,8 & 90,9 \\
\hline TV5 - Representante de Dureza & 2,26 & 0,82 & 8,4 & 31,4 & 43,6 & 16,6 \\
\hline TV6 - Desumanizante e Desgastante & 1,23 & 0,63 & 45,6 & 43,9 & 10,5 & - \\
\hline \multicolumn{7}{|c|}{ Atributos Descritivos ( $F=258,22$ para $p<0,001)$} \\
\hline TD2 - Ocupar-se & 3,43 & 0,43 & - & 0,7 & 14,5 & 84,8 \\
\hline $\begin{array}{l}\text { TD3 - Ser Responsável, Desafiar-se e Crescer } \\
\text { Economicamente }\end{array}$ & 3,41 & 0,44 & - & 0,7 & 14,9 & 84,5 \\
\hline TD4 - Realizar-se e Sentir-se Útil & 3,03 & 0,57 & - & 6,1 & 39,2 & 54,7 \\
\hline TD1 - Fazer Esforço Corporal e Desumanizar-se & 2,66 & 0,60 & 1,0 & 12,2 & 57,1 & 29,7 \\
\hline TD5 - Ser Reconhecido e Tratado com Justiça & 2,49 & 0,67 & 1,4 & 24,0 & 52,0 & 22,6 \\
\hline
\end{tabular}

* O número de participantes não corresponde ao total da amostra ( $\mathrm{N}=302)$, pois nem todos os participantes conseguiram responder ao questionário IST. 
a característica mais percebida no trabalho concreto. Nos dois últimos tipos, apresentando as menores médias, os respondentes encontram-se distribuídos entre os intervalos, especialmente em ser reconhecido e tratado com justiça (TD5). Há grupos que reconhecem esse tipo em sua rotina de trabalho, pois $22,6 \%$ dos participantes apresentam escores acima de 3 , e $52 \%$, entre 2 e 3 . Entretanto, uma parcela considerável $(25,4 \%)$ apresentou escores abaixo de 2 , ou seja, percebe-se pouco a nada reconhecida e/ou tendo seus direitos pouco respeitados (injustiça). Esses resultados contrastam-se com os do tipo mais valorizado (expressão de respeito e de acolhimento), como exemplifica um operário:

Então, o que falta mesmo na construção civil é reconhecimento de algumas pessoas. (...) Tem muita gente boa por aí e às vezes não tem reconhecimento. Não é o meu caso (...) eu já cheguei aqui no patamar máximo que eu podia chegar com o meu grau de estudo, porque eu tenho primeiro grau (Entrevista 15 - Operário).

Para avaliar a centralidade do trabalho, estimaremos as médias, o desvio-padrão e a frequência dos participantes em cada nível de ordenação atribuído às esferas de vida (tabela 6).

Considerando-se as médias como critério para indicar a ordem tendencial da amostra, as esferas de vida estão ordenadas na mesma sequência posta na tabela 6 . Entretanto, a observação detida na distribuição das respostas para cada esfera põe em dúvida a adequação dessa medida para representá-la. A religião seria tendencialmente a segunda esfera? As frequências levantadas indicam que apenas 40 participantes $(13,3 \%)$ de fato se identificam com tal tendência. A distribuição é realmente bimodal. Há 99 pessoas (33\%) que tomam a religião como a esfera mais importante e $71(23,7 \%)$ que a tomam como a quarta esfera de vida. Essa valorização da esfera religião foi associada ao trabalho, nas entrevistas, como uma forma de receber aprovação divina: “(...) Deus abençoa cada dia que a gente acorda de madrugada e traz a gente com segurança porque é uma coisa honesta que a gente tá fazendo (...)" (Entrevista

\section{3 - Operário).}

A esfera trabalho, segundo as médias, ocupou o terceiro lugar na ordem de importância, divergindo da segunda posição encontrada por Borges (1998a). Nas entrevistas, há expressão da associação entre trabalho e família, em que o primeiro provê a segunda: “(...) porque, se eu não trabalhar, eu não vou ter dinheiro, não vou poder adquirir, assim, bens materiais, né? Que através dos bens materiais agente adquire conforto, ter o do bom e o do melhor em casa" (Entrevista 14 Operário).

Apesar da divergência observada quanto à posição, a inter-relação entre as esferas família, religião e trabalho parece ser uma característica da ocupação, corroborada por Borges, Barros e Peixoto (2014), em que a prática religiosa é vivenciada junto à família, cujos princípios são vistos como importantes para a estruturação desta e para uma boa conduta no trabalho, e por Cockell e Perticarrari (2010), em que o trabalho foi apontado pelos operários como meio de se tornarem os provedores da família e de exercerem sua responsabilidade para com ela.

Identificamos, então, os padrões dos significados do trabalho (tabela 7), os quais apresentam os diferentes modos como os operários constroem e compartilham os significados do trabalho no dia a dia de suas atividades. Estudos sobre o trabalho na construção civil destacam as condições de trabalho precárias, direitos trabalhistas muitas vezes burlados, discriminação devido ao baixo nível de instrução e de especialização profissional, entre outros (Borges, 1998a; Cockell, 2008; P. H. F. Santos, 2010; Sousa, 1983). Nos padrões identificados, tais aspectos são vivenciados de maneiras distintas pelos operários, tendo o trabalho adquirido conotações mais positivas seja no que se espera dele, seja no que ele tem sido (otimista, satisfeito e indiferente expressivo) ou negativas (crítico). Apesar das distinções, a visão de um trabalho que respeite e acolha o trabalhador mostrou-se ser valorizada e desejada por todos eles.

\section{Tabela 6}

Organização das cinco esferas de vida, conforme a ordem de importância $(n=300)$

\begin{tabular}{|c|c|c|c|c|c|c|}
\hline & $\begin{array}{l}\text { Média (desvio- } \\
\text { padrão) }\end{array}$ & $\frac{1}{\mathrm{n}(\%)}$ & $\frac{2}{\operatorname{n~(\% )}}$ & $\frac{3}{n(\%)}$ & $\frac{4}{\operatorname{nn}(\%)}$ & $\frac{5}{n(\%)}$ \\
\hline Família & $4,14(0,84)$ & $113(37,7)$ & $131(43,7)$ & $46(15,3)$ & $7(02,3)$ & $3(01,0)$ \\
\hline Religião & $3,22(1,53)$ & $99(33,0)$ & $40(13,3)$ & $39(13,0)$ & $71(23,7)$ & $51(17,0)$ \\
\hline Trabalho & $2,84(1,02)$ & $10(03,3)$ & $66(22,0)$ & $135(45,0)$ & $47(15,7)$ & $42(13,9)$ \\
\hline Lazer & $2,49(1,26)$ & $35(11,7)$ & $26(08,7)$ & $57(19,0)$ & $114(38,0)$ & $68(22,7)$ \\
\hline Comunidade & $2,30(1,49)$ & $42(14,0)$ & $38(12,7)$ & $24(08,0)$ & $59(19,7)$ & $137(45,7)$ \\
\hline
\end{tabular}




\section{Relação entre os significados do dinheiro e do tra- balho}

Para a análise da relação entre os padrões dos significados do dinheiro e do trabalho, realizamos teste quiquadrado $(\chi 2=17,62 ; \mathrm{p}<0,05)$, o qual rejeitou a independência entre as duas distribuições (figura 1), significando que aquelas encontradas diferem do que seria esperado ao acaso. $\mathrm{O}$ grupo que atribui ao trabalho conotações de otimismo é o que menos percebe o dinheiro como gerador de conflito (padrão conflitante). $\mathrm{O}$ grupo do padrão de significado do trabalho crítico é o que menos atribui conotações coletivistas ao dinheiro e o que expressa com mais frequência os padrões de significado do dinheiro conflitante e pessimista. Os participantes do padrão satisfeito apresentam-se dispersos entre os padrões dos significados do dinheiro. O grupo do padrão indiferente expressivo do significado do trabalho tem uma forte tendência a apresentar o padrão do significado do dinheiro coletivista expressivo e a ser menos frequente no padrão pessimista.

Assim, a importância atribuída ao trabalho, a proximidade/distanciamento entre o trabalho ideal e o real (atributos valorativos e descritivos) e os diferentes níveis de concordância com os componentes do significado do trabalho são construídos conjuntamente com os significados que o dinheiro assume para essa categoria ocupacional. Corrobora, portanto, a literatura que aponta para a relação existente entre o trabalho e o dinheiro nas sociedades capitalistas (Barracho, 2001; Brief \& Nord, 1990). Tal observação está ilustrada nas

Tabela 7

Padrões dos significados do trabalho

\begin{tabular}{|c|c|c|}
\hline $\begin{array}{l}\text { Padrões dos } \\
\text { significados do } \\
\text { trabalho }\end{array}$ & $\mathbf{N}^{*}$ & Descrição \\
\hline
\end{tabular}

\begin{tabular}{|c|c|c|}
\hline Otimista & 105 & $\begin{array}{l}\text { A importância do trabalho é vista moderadamente. Há o predomínio de escores mais elevados nos } \\
\text { tipos valorativos, em comparação aos demais grupos, destacando-se o tipo Expressão de Respeito e } \\
\text { de Acolhimento (TV2). Entre os descritivos, o escore mais alto encontra-se em Ocupar-se (TD2) e o } \\
\text { mais baixo em Ser Reconhecido e Tratado com Justiça (TD5). Pode-se dizer que para esse grupo, o } \\
\text { trabalho é visto de maneira mais otimista, à medida que incorporam os aspectos mais positivos do } \\
\text { que o trabalho deva ser, e reconhecem muitos desses aspectos na rotina de trabalho. }\end{array}$ \\
\hline
\end{tabular}

Esse grupo atribui importância moderada à esfera trabalho. 0 escore mais alto dos tipos valorativos encontra-se em Expressão de Respeito e de Acolhimento (TV2) e o mais baixo em Desumanizante e

Crítico Desgastante (TV6). Há um predomínio de escores baixos nos tipos descritivos, em relação aos demais grupos, sendo o menor deles o Ser Reconhecido e Tratado com Justiça (TD5). Para esse grupo há uma diferença entre o que se acredita que o trabalho deve ser e a percepção do que ele é de fato, cuja realidade encontra-se aquém daquilo que se tem como ideal.

\begin{tabular}{ll}
\hline & O trabalho é visto como a segunda esfera mais importante na vida. Há predomínio de escores \\
moderados nos tipos valorativos, destacando-se o tipo Fonte de Realização e Independência \\
Econômica (TV1). O tipo Desgastante e Desumanizante (TV6) apresentou escore mais baixo no \\
grupo e, ao mesmo tempo, mais elevado em relação aos demais. Sobre os tipos descritivos, há \\
predomínio de escores mais elevados, tendo o Ocupar-se (TD2) como o mais percebido e Fazer \\
Esforço Corporal e Desumanizar-se (TD1) como o menos percebido. É o grupo que apresenta maior \\
coerência entre aquilo que o trabalho deve ser e aquilo que tem sido na realidade.
\end{tabular}

* $\mathrm{N}$ (Número de participantes) 
construções simbólicas de ambos os fenômenos, os quais revelam elementos caracterizadores do capitalismo, como desigualdade, sofrimento e prazer (significados do dinheiro), e desumanizante e desgastante, realização e independência econômica e realizar-se e sentir-se útil (significados do trabalho). Esses conteúdos, como sinalizados desde o início deste artigo, guardam as contradições do contexto forjadas pelo sistema capitalista.

O teste estatístico aplicado reconhece as interfaces entre os dois fenômenos, enquanto as distribuições assinalam também que, apesar das interfaces, não são totalmente dependentes um do outro. Em última análise, sublinha a distinção entre os fenômenos em suas multideterminações (p. ex., trajetórias individuais, experiências de trabalho e diferenças entre as organizações), não exploradas na presente pesquisa.

\section{CONSIDERAÇÕES FINAIS}

Os resultados demonstraram relação entre os significados do dinheiro e do trabalho para os operários da construção de edificações, atingindo, assim, o objetivo proposto na pesquisa. Também demonstraram, corroborando a literatura consultada, a diversidade de significados atribuídos ao trabalho e ao dinheiro. Como entre os pressupostos assumidos na pesquisa estava a

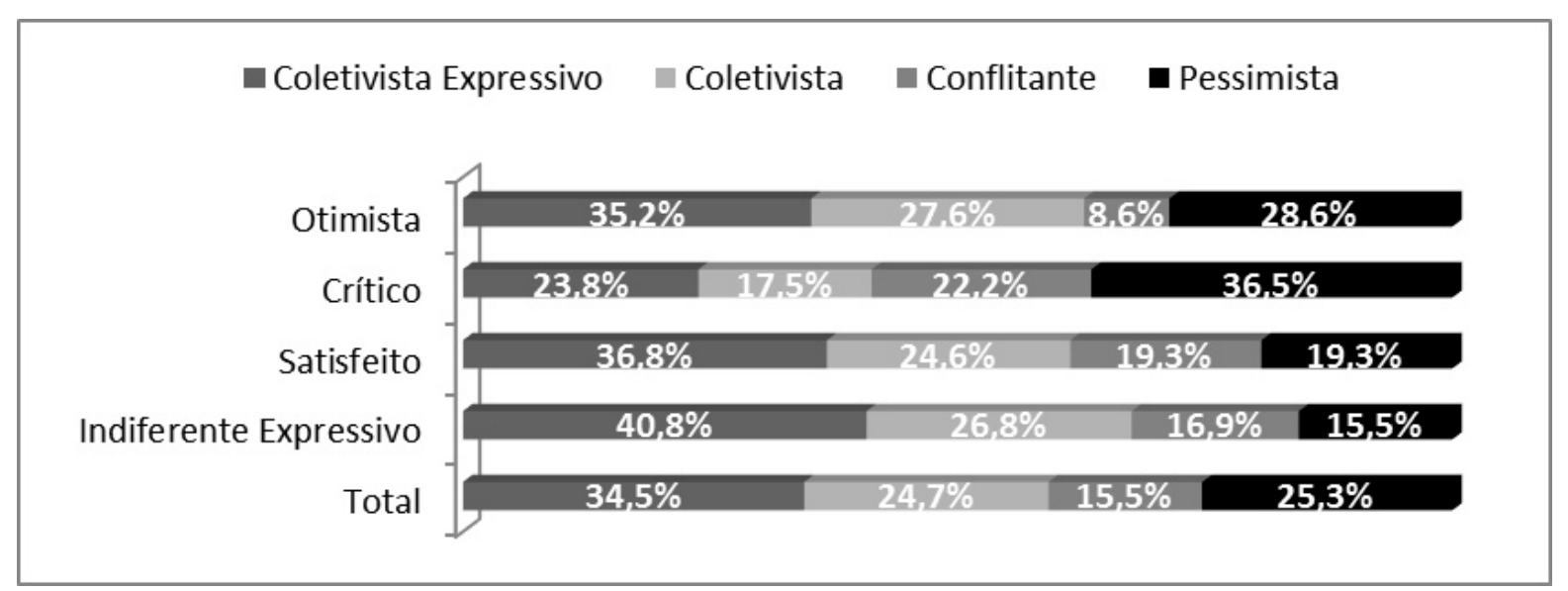

Figura 1. Cruzamento entre os padrões dos significados do dinheiro e do trabalho.

noção de que os atos de significados afetam a vida cotidiana das pessoas, levantamos como tais significados se imbricam nos sentidos atribuídos às decisões de gestão das organizações e à adoção de políticas. Por exemplo, uma organização pode adotar um aumento salarial substancial para combater a rotatividade. Para os trabalhadores que apresentam os padrões de significado do trabalho crítico e do dinheiro pessimista, essa decisão terá o mesmo impacto que para os demais? Ou será que esse grupo, para aproximar o trabalho ideal e o real, tende a valorizar menos medidas econômicas do que outros caminhos? A medida de aumento salarial demanda ser aliada a outras medidas de transformação do trabalho, incluindo os aspectos interpessoais hierárquicos?

A frequência com que surgiram significados do dinheiro em que prevalecem valores coletivistas (transcendência, altruísmo e preocupação com as desigualdades) e a importância atribuída à família transmitem o que para gestores organizacionais? Propi- ciar possibilidade de aumento de renda por meio de prorrogação da jornada criaria, então, o dilema para o operário entre as vantagens econômicas a serem conquistadas e o convívio familiar? Interessa à efetividade organizacional tal dilema? Programas de complementação salarial fundamentados no desempenho individual e na competitividade entre os trabalhadores potencializam os valores predominantes associados ao dinheiro ou contradizem os interesses dos operários? Tendem a mobilizar a adesão efetiva de todos os grupos de trabalhadores?

Esses questionamentos aqui levantados são exemplos da aplicabilidade que compreender as interfaces dos dois fenômenos pode adquirir na gestão do trabalho nas organizações. Entretanto, apropriar-se desses significados também pode embasar reflexões no campo trabalhista e/ou de organização do trabalhador. Indagações sobre isso também podem ser levantadas. Para cada grupo de trabalhador, segundo os padrões de 
significado do trabalho e do dinheiro, qual é o sentido, por exemplo, de pautas de reivindicações sobre condições de trabalho? As pautas e prioridades estabelecidas nas negociações coletivas atendem a que grupos de trabalhadores? Será que pensar no que significam o dinheiro e o trabalho pode contribuir para a reflexão sobre quais realmente são as aspirações dos trabalhadores?

Assinalamos que algumas limitações desta pesquisa, como a utilização de uma ficha sociodemográfica bastante reduzida, tal como a quantidade de organizações participantes, não possibilitaram explorar outros aspectos dos fenômenos estudados. Embora não tenham sido incluídas aqui, para preservação do anonimato dos participantes, variáveis como a renda e a função ocupada poderiam ampliar as discussões, oferecendo informações mais ricas sobre as diferentes pressões a que esses trabalhadores (p. ex., serventes, pedreiros) estão sujeitos no dia a dia e como isso impacta a elaboração dos significados do dinheiro e do trabalho. Da mesma forma, ampliando o número de organizações, é possível comparar, por exemplo, as práticas de gestão de pessoas e o modo como os trabalhadores, nesses diferentes contextos, absorvem e/ou respondem a tais práticas, a partir dos símbolos construídos sobre o dinheiro e o trabalho. Entendemos, por fim, que os exemplos de questionamentos aqui levantados, tendo em vista a aplicabilidade do conhecimento produzido, bem como os limites apresentados, podem servir como sugestões para pesquisas futuras.

\section{REFERÊNCIAS}

Álvaro, J. L., Bergère, J., Crespo, E., Torregrosa, J. R., \& Garrido, A. (1995). The meanings of work in Spain. International Journal of Sociology and Social Policy, 15(6), 59-67.

Aktouf, O. (1986). Une visíon interne des rapports de travail: le cas de deux brasseries. Le travailhumain, 49(3), 237 248.

Antunes, R. (1995). Adeus ao trabalho? Ensaio sobre as metamorfoses e a centralidade do mundo do trabalho. São Paulo: Cortez.

Ardichvili, A. (2005). The meaning of working and professional development needs of employees in a post-communist country. Cross Cultural Management, 5(1), 105-119.

Barracho, C. (2001). Lições de Psicologia Económica. Lisboa: Instituto Piaget.

Bastos, A. V. B., Pinho, A. P. M., \& Costa, C. A. (1995). Significado do trabalho: um estudo entre trabalhadores inseridos em organizações formais. Revista de Administração de Empresas, 35(6), 20-29.

Borges, L. O. (1996). A representação social do trabalho: um estudo empírico com trabalhadores da construção civil, indústria de confecções e costura e comércio de Brasília. Estudos de Psicologia (Natal), 1(1), 7-25.

Borges, L. O. (1998a). O significado do trabalho e socialização organizacional: um estudo empírico entre trabalhadores da construção habitacional e de redes de supermercados. Tese de doutorado. Universidade de Brasília, Brasília.

Borges, L. O. (1998b). Os pressupostos dos estudos do significado do trabalho na psicologia social: no caminho do existencialismo. Vivência, 12(2), 87-105.

Borges, L. O., \& Barros, S. C. (2015). Inventário de significado do trabalho para trabalhadores de baixa instrução. In K. Puente-Palácios \& A. Peixoto (Coords.), Ferramentas de diagnóstico para organizações e trabalho: Um olhar a partir da Psicologia (pp. 232-260). Porto Alegre: Artmed.

Borges, L. O., Barros, S. C., \& Peixoto, T. P. (2014). Os operários e suas esferas de vida. In V. F. Quiroga \& M. R. Cattaneo (Comp.), Transformaciones en las Organizaciones del Trabajo: Salud y Ampliación de Ciudadanía Tomo I (pp. 115-124). Rosario: UNR Editora.

Borges, L. O.,\& Peixoto, T. P. (2011). Ser operário da construção civil é viver a discriminação social. Revista Psicologia: Organizações e Trabalho, 11(1), 21-36.

Borges, L. O.,\& Pinheiro, J. Q. (2002). Estratégias de coleta de dados com trabalhadores de baixa escolaridade. Estudos de Psicologia (Natal), 7 (Número Especial), 53-63.

Borges, L. O.,\&Tamayo, A. (2001). A estrutura cognitiva do significado do trabalho. Psicologia: Organizações e trabalho, 1(2), 11-44.

Borges, L. O.,\& Yamamoto, O. H. (2010). O significado do trabalho para psicólogos brasileiros. In A. V. B. Bastos \& S. M. G. Gondim (Orgs.), O Trabalho do Psicólogo no Brasil (pp. 241-282). São Paulo: ARTMED.

Borges, L. O.,Tamayo, A., \& Alves-Filho, A. (2005). Significado do trabalho entre profissionais de saúde. In: L. O. Borges (Org.), O profissional de saúde e seu trabalho (pp. 143-198). São Paulo: Casa do Psicólogo.

Borsato, J. M. L. S., Gomes, T. G., Pimenta, D. P., Carvalho, L. F., \& Ribeiro, K. C. S. (2010). Significado do Dinheiro: Uma Análise Comparativa entre Indivíduos Adimplentes e Inadimplentes [Resumo]. In Programa de Pós-graduação em Administração da FEA-USP (Org.), XIII Seminários em Administração (SEMEAD). Anais (pp.1-17). São Paulo: Faculdade de Economia, Administração e Contabilidade da USP.

Brief, A. P., \& Nord, W. R. (1990). Work and meaning: definitions and interpretations. In: A. P. Brief, \& W. R. Nord (Orgs.), Meanings of occupational work: a collections of essays (pp. 1-19). Massachusetts/Toronto: Lexington Books.

Bruner, J. (1997). Actos de Significado - para uma psicologia cultural (V. Prazeres, Trad.). Lisboa: Edições 70.

Cifre, E., Martínez, I., Llorens, S., \&Salanova, M. (2001). Patrones de significado Del trabajo, características del puesto y bienestar psicológico em trabajadores de produccíon. Revista de Psicología, 23, 94-113.

Cockell, F. F. (2008). Da enxada à colher de pedreiro: trajetórias de vulnerabilidade social na construção civil. Tese 
de doutorado, Universidade Federal de São Carlos, São Carlos.

Cockell, F. F., \& Perticarrari, D. (2010). Contratos de boca: a institucionalização da precariedade na construção civil. Caderno CRH, 23(60), 633-653.

Dakduk, S., Gozález, A., \& Montilla, V. (2008). Relación de variables sociodemográficas, psicológicas y la condición laboral conel significado del trabajo. Interamerican Journal of Pshycology,42(2), 390-401.

DIEESE, Departamento Intersindical de Estatística e Estudos Socioeconômicos (2011). Estudo Setorial da Construção. Recuperado em julho de 2011, de <http://www.dieese.org.br/esp/estPesq56ConstrucaoCivil.pdf $>$.

Furnham, A. (1984). Many sides of the coin: The psychology of Money usage. Personality \& Individual Differences, 5(5), 501-509.

Harpaz, I., \& Meshoulam, I. (2010).The meaning of work, employment relations, and strategic human resources management in Israel. Human Resource Management Review, 20, 212-223.

Katzell, R. (1994). Contemporary Meta-Trends in Industrial and Organizational Psychology. In H. C. Triandis, M. D. Dunnette, \& L. M. Hough (Orgs.), Handbook of Industrial \& Organizacional Psychology, Vol.4 (pp.1-94). California: Palo Alto.

Martin-Baró, I. (1990). ¿Trabajador alegre o trabajador explotado? La identidad del salvadoreño. Revista Interamericana de Psicologia, 24(1), 1-24.

Marx, K. (1980). O Capital: crítica da economia política (R. Sant'Anna, Trad.). Rio de Janeiro: Civilização Brasileira. (Originalmente publicado em 1890).

Mello, L. C. B.; \& Amorim, S. R. L. (2009). O subsetor de edificações da construção civil no Brasil: uma análise comparativa em relação à União Européia e aos Estados Unidos. Produção, 19(2), 388-399.

Moreira, A. S. (2000). Valores e dinheiros: um estudo das relações entre prioridades de valores e significado do dinheiro para indivíduos. Tese de doutorado não publicada, Universidade de Brasília, Brasília.

Moreira, A. S. (2002). Dinheiro no Brasil: um estudo comparativo do significado do dinheiro entre as regiões geográficas brasileiras. Estudos de Psicologia (Natal), 7(2), 379-387.

Moreira, A. S., Caldas, C. E. G., \& Atayde, F. A. (2002). ESD II- revendo a estrutura conceitual do significado do dinheiro [Resumo]. In Sociedade Brasileira de Psicologia (Org.), XXXII Reunião Anual de Psicologia. Resumos (pp.391-392).Florianópolis: SBP.

MOW International Research Team (1987). The meaning of working. London: Academic Press.

Oliveira, J. C. V. (2010). Valores do dinheiro: uma análise da influência da percepção do dinheiro na escolha da profissão. Dissertação de mestrado. Universidade Federal de Santa Maria, Santa Maria.
PED, Pesquisa de Emprego Desemprego (2012). Mercado de trabalho metropolitano em 2011. Recuperado em fevereiro de 2012, de <http://www.seade.gov.br/produtos/ped/metropolitana/anual/pdf/metropolitano_anual_20 11.pdf $>$.

Santos, C. A. (2006). Significado do Trabalho e Conduta Ético-profissional: um estudo de caso na Polícia Militar Baiana. Dissertação de mestrado. Universidade Federal da Bahia, Salvador.

Santos, P. H. F. (2010). "Deus lhe pague!” A condição servente na construção civil. Dissertação de mestrado, Universidade Federal de Minas Gerais, Belo Horizonte.

Sato, L. (1993). A representação social do trabalho penoso. In M. J. Spink. (Org.), O conhecimento no cotidiano (pp. 188-211). São Paulo: Brasiliense.

Simmel, G. (2005). The Phylosophy of Money. London and New York: Routledge. (Originalmente publicado em 1907).

Soares, C. R. V. (1992). Significado do trabalho: um estudo comparativo de categorias ocupacionais. Dissertação de Mestrado. Universidade de Brasília.

Souza, N. H. B. (1983). Construtores de Brasília. Petrópolis: Vozes.

Tang, T. L. P. (1993). The meaning of money: Extension and exploration of the money ethic scale in a sample of university students in Taiwan. Journal of Organizational Behavior, 14, 93-99.

Távora, G. G. (2003). As relações entre significado do dinheiro e significado do salário para motoristas e cobradores de transporte coletivo urbano. Dissertação de mestrado. Universidade Federal do Pará, Belém.

Varella, J. M. C.,\& Borges, L. O. (2012). Significados do trabalho e motivações dos bancários: comparando dois momentos da reestruturação produtiva. In L. O. Borges, G. E. Vitullo, J. R. T. Ponte. (Org.), Ser bancário: Viver o esplendor social ou o trabalho bancário? (pp. 119-140). Curitiba: Editora CRV.

Vilela, E. C. (2003). Significado do trabalho e escolha profissional: um estudo com universitários primeiranistas. Dissertação de mestrado não-publicada, Universidade Federal do Rio Grande do Norte, Natal.

Wernimont, P. F., \& Fitzpatrick, S. (1972). The meaning of money. Journal of Applied Psychology, 56(3), 218-226.

Yamauchi, K. T., \& Templer, D. I. (1982). The development of a money attitude scale. Journal of Personality Assessment, 46(5), 522-528.

\section{Notas:}

1 Mestre em Psicologia (UFMG). Doutoranda em Psicologia pelo Programa de Pós-graduação em Psicologia da UFMG.

2 Doutora em Psicologia pela Universidade de Brasília. Professora Adjunta do Departamento de Psicologia da Universidade Federal do Rio Grande do Norte. Contato: liviadeoliveira@gmail.com 